A.Г.Малявин

Использование физических факторов

в лечении и реабилитации больных бронхиальной астмой

ГУ НИИ пульмонологии МЗ и СР РФ, Москва

\title{
A.G.Maliavin \\ Physiotherapeutic methods in treatment and rehabilitation of the patients with asthma
}

\begin{abstract}
Summary
Effect of different physiotherapeutic methods (transcranial electromagnetic stimulation combined with other positions of electrodes (adrenal glands, spleen, thymus or thyroid gland); transcranial electric impulse therapy; cryomassage of the chest; interval normobaric hypoxic training and silvinite speleotherapy) on clinical signs, blood and sputum laboratory parameters, immune and endocrine systems, spirographic, echocardiographic and cardiointervalographic parameters were investigated in 308 patients with moderate asthma.

As a result efficacy of the methods was evaluated and differentiated indications for their administration were developed with regards to characteristic features of the disease and co-morbid status.

\section{Резюме}

Изучено влияние различных видов физиотерапевтических воздействий (комбинированные электромагнитные воздействия трансцеребрально и на области надпочечников, селезенки, тимуса и щитовидной железы; электроимпульсных трансцеребральных воздействий; криомассажа грудной клетки; интервальной гипоксической тренировки и сильвинитовой спелеотерапии) на динамику клинических параметров, лабораторных показателей анализов крови и мокроты, иммунологических и эндокринных показателей, данных спирографии, эхокардиографии и вариационной кардиоинтервалографии у 308 больных среднетяжелой бронхиальной астмой. На основании полученных результатов определена эффективность изученных методик, разработаны дифференцированные показания к их назначению с учетом особенностей течения заболевания и сопутствующей патологии.
\end{abstract}

\section{Актуальность проблемы}

В последние годы достигнут существенный прогресс в понимании патогенеза бронхиальной астмы (БА), и это позволило выработать согласованную концепцию лечения, в которой основной упор сделан на базисную медикаментозную терапию, что вполне оправдано с точки зрения современных взглядов на сущность заболевания [1]. В то же время в клинической практике хорошо известны ситуации, когда при наличии сопутствующей патологии, плохой переносимости, тахифилаксии, побочных эффектов или иных причин применение медикаментов ограничено или желательна его минимизация, что и может быть решено путем включения в лечебно-реабилитационную программу средств физиотерапии.

Как показывают многочисленные исследования, физические факторы способны внести весомый вклад в процесс лечения и реабилитации больных БА. Комплексное действие физических факторов достигается, с одной стороны, их физическими особенностями, проникающей способностью, адекватностью физическим процессам в организме и возможностью влияния на регулирующие системы [2], а с другой оно предопределено многофакторностью аллергического воспаления при БА и заинтересованностью разнообразных систем организма в их реализации. K сожалению, многие предложенные методики физической терапии БА представлены без сравнительного анализа и определения четких критериев их назначе- ния. Мало публикаций по длительному наблюдению результатов использования физиотерапии, что не позволяет объективно определить ее возможности и эффективность в сочетании с медикаментозной терапией. В то же время, не противопоставление лекарственной и немедикаментозной терапии БА, а их разумное сочетание, учитывая свойственное физическим факторам длительное последействие, а также немаловажный психологический аспект, дает возможность существенно повысить эффективность лечебно-реабилитационных мероприятий [3].

Объектами изучения в настоящей работе стали разные по своей сущности и механизмам действия физические факторы. Их анализ в одной статье позволяет не только осуществить простое сравнение эффективности при БА, но и получить полезные сведения об особенностях их применения, возможных специфических показаниях в зависимости от фазы, степени тяжести и особенностей течения заболевания, от сопутствующей патологии, оценить длительность последействия и способность влиять на характер течения БА. В практическом плане по результатам исследования может быть осуществлен выбор наиболее адекватной методики для включения в лечебно-реабилитационную программу, сочетающую базисную медикаментозную терапию и различные физические факторы, что важно с точки зрения оптимизации лечения. 
Цель исследования - изучить влияние физических факторов, определить их роль, место и эффективность в процессе лечения и реабилитации больных БА в зависимости от варианта течения, степени тяжести патологического процесса и сопутствующей патологии.

\section{Дизайн исследования}

Проведено открытое когортное проспективное исследование, в котором методом простой рандомизации больные были разделены на клинически сопоставимые группы. Всем больным назначали адекватную базисную медикаментозную терапию и курс лечебной физкультуры. Клинические, инструментальные и лабораторные исследования проводили в 3 этапа: до лечения, после курса лечения и в отдаленный период через 6-12 мес.

\section{Характеристика обследованных больных}

Для решения поставленных задач обследованы 308 больных БА в возрасте от 16 до 67 лет (в среднем $-43,2 \pm 5,2$ года) с давностью заболевания от 1 до 22 лет (в среднем - 8,1 $\pm 2,1$ года). Основные сведения представлены в табл. 1 .

\section{Методики исследования}

Исследования проводили с использованием стандартизованных индивидуальных карт. Клинически оценивали количество приступов экспираторного диспноэ, провоцирующие их факторы, одышку вне приступов, характер кашля и количество используемых медикаментов. Всем больным проводили ис-

Таблица 1 Характеристика обследованных больных

\begin{tabular}{|l|r|}
\hline \multicolumn{1}{|c|}{ Признаки } & Количество больных \\
Пол & \\
мужской & $123(39,9 \%)$ \\
женский & $185(60,1 \%)$ \\
\hline Возраст (лет) & $36(11,7 \%)$ \\
$15-25$ & $89(28,9 \%)$ \\
$26-45$ & $120(39 \%)$ \\
$46-55$ & $63(20,5 \%)$ \\
$56-67$ & \\
Клинико-патогенетический вариант & $240(77,9 \%)$ \\
экзогенный & $68(22,1 \%)$ \\
эндогенный & \\
\hline Фаза заболевания & $95(30,8 \%)$ \\
обострение & $213(69,2 \%)$ \\
неполная ремиссия & \\
\hline Тяжесть течения заболевания & $46(14,9 \%)$ \\
легкая & $262(85,1 \%)$ \\
среднетяжелая & \\
\hline Сопутствующие заболевания & $152(49,4 \%)$ \\
ХОБЛ & $108(35,1 \%)$ \\
тиреоидит & $87(28,2 \%)$ \\
поллиноз & $64(20,8 \%)$ \\
гипертоническая болезнь & $47(15,3 \%)$ \\
ИБС & \\
\hline
\end{tabular}

следование ФВД с анализом кривой "поток-объем" на компьютерных спироанализаторах Fukuda и Pulmotest, ЭКГ; оценивали клинический анализ крови и мокроты, биохимический анализ крови с определением уровней СРБ гексоз-орциновым методом, фибриногена, церулоплазмина модифицированным методом Ревина, серотонина методом Snyder в модификации В.И.Кулинского и А.С.Костюковской и гистамина методом Шора.

Иммунологическое исследование включало в себя определение содержания в периферической крови циркулирующих иммунных комплексов и иммуноглобулинов методом радиальной иммунодиффузии по G.Mancini, Т- и В-лимфоцитов методом розеткообразования по M.Jondal et al. и субпопуляций Т-лимфоцитов по методу Moretta et al. Проводили также реакцию бласттрансформации лимфоцитов (РБТЛ) с фитогемагглютинином.

По показаниям проводили рентгенологические исследования органов грудной клетки. У больных 1-й группы (комбинированные воздействия ЭМВ) радиоиммунологически определяли в периферической крови содержание АКТГ, альдостерона и кортизола. У больных 2-й группы (СМТ-электросон) дополнительно проводили УЗИ щитовидной железы (ЩЖ) и радиоиммунологическое исследование содержания в периферической крови кортизола, трийодтиронина, тироксина, тиреотропного гормона, тиреоглобулина, тироксинсвязывающего глобулина и антител к тиреоглобулину. Больным 4-й группы (ИГТ) дополнительно назначали ЭхоКГ и кардиоинтервалографию.

Полученные результаты проанализированы с использованием методов вариационной статистики с учетом числа параметров и их распределения (параметрический тест Стьюдента, непараметрический тест Вилкоксона, коэффициент корреляции Пирсона) на основе компьютерной программы Statistica.

\section{Подразделение больных на группы и описание лечебных методик}

В группе сравнения (32 больных), сформированной методом случайной выборки, помимо базисной медикаментозной терапии и лечебной гимнастики назначали ложные процедуры электромагнитной или электроимпульсной терапии без включения выходной мощности аппаратов.

Больным 1-й группы назначали трансцеребрально ЭП УВЧ (27,12 МГц). Конденсаторные пластины диаметром 12 см от аппарата "Ундатерм 80-1" располагали битемпорально с фиксированным зазором по 2,5 см с каждой стороны. В течение первых 3 процедур время воздействия увеличивали последовательно от процедуры к процедуре - 5-15 мин, используя 4-ю ступень мощности аппарата, затем повышали ступень мощности на 1 градацию и также последовательно увеличивали продолжительность воздействия, затем еще увеличивали ступень мощности (6-я ступень, 60 Вт) и также доводили длительность 
процедур до максимальной (15 мин), затем с этими параметрами проводили последующие процедуры. На курс назначали 20 процедур ежедневно. Через день (на курс - 10 процедур) через 15 мин после процедур трансцеребрального воздействия ЭП УВЧ дополнительно проводили процедуры ДМВ-терапии (ЭМП СВЧ, 460 МГц, 3-я ступень мощности (35-40 Вт) аппарата "Волна-2") продолжительностью по 10 мин. Прямоугольный излучатель 16 × 35 см располагали с зазором 3-5 см у больных группы 1А (35 пациентов) над поясницей, на уровне Th10-L4, над областью проекции надпочечников, у больных группы 1Б (59 пациентов) - над областью проекции селезенки, косо вдоль Х-XII ребер - между переднеподмышечной и заднеподмышечной линиями, у больных группы 1В (7 пациентов) - над областью проекции тимуса и ЩЖ, над передней поверхностью шеи и верхней частью грудины.

2-я группа была разделена на 2: в подгруппу 2А (31 пациент) вошли больные БА без сопутствующей патологии ЩЖ, а в подгруппу 2Б (34 пациента) больные БА с сопутствующими заболеваниями ЩЖ. Всем этим больным на фоне базисной терапии назначали по 10-12 ежедневных процедур трансцеребрального (глазнично-сосцевидное расположение электродов) воздействия СМТ от аппарата "Амплипульс-5". Использовали переменный режим, III род работы, соотношение длительности посылок и пауз $1: 1,5$, частоту 30 Гц, глубину модуляций $59 \%$, силу тока - до достижения ощущения вибрации под электродами (в среднем - 2-2,5 мА), время воздействия - 15 мин.

Больным 3-й группы (35 пациентов) назначали 8-10 ежедневных процедур криотерапии, которая заключалась в поглаживании асимметричных зон грудной клетки и живота (спереди - верхней части левой половины грудной клетки и правой половины живота, сзади - правой половины поясницы и правой половины грудной клетки до угла лопатки и левого надплечья и левой лопатки) криопакетами до достижения кожной гипоэстезии (3-5 мин). Объем криопакетов составлял 300-500 мл, до процедуры их охлаждали в морозильной камере до температуры $-22{ }^{\circ} \mathrm{C}$. Проводили 4 цикла (по 2 спереди и сзади) с интервалом 1,5-2 мин, общая продолжительность процедуры - 17-26 мин.

Пациенты 4-й группы (25 больных) на фоне базисной терапии получали по 10-12 ежедневных процедур ИГТ. Она заключалась в попеременном вдыхании воздушной гипоксической смеси из аппарата гипоксикатора с концентрацией кислорода 10-12\% (3-5 мин) и атмосферного воздуха (5 мин). За процедуру использовали 4-5 циклов. В 5-й группе (50 пациентов) использовали сильвинитовую спелеотерапию. Ежедневно в течение 12-15 дней больные по 45 мин находились в микроклимате искусственной сильвинитовой спелеокамеры "Спеклика-1" при температуре $20-22{ }^{\circ} \mathrm{C}$ и относительной влажности $65 \%$.

Полная информация о составе групп больных представлена в табл. 2.

Клиническая эффективность изучавшихся лечебных методик продемонстрирована в табл. 3. При этом следует отметить хорошую переносимость и седативный эффект процедур во всех группах, кроме группы 1В, в которой отмечались плохая переносимость процедур и высокая частота обострений БА. Более раннее начало клинической динамики, которая, как правило, выражалась начиная с 3-4 процедуры, являлось предиктором более выраженного клинического эффекта по окончании курса лечения. В отдаленный период отмечалось урежение частоты заболеваемости ОРВИ или изменение характера последствий, заключающееся в том, что ОРВИ перестали вызывать закономерные до начала курса лечения обострения БА.

Относительно более высокая эффективность лечения отмечена в группе 1 А у больных с обильным выделением мокроты и при астматической триаде, в группе 1Б - у больных с атопической сенсибилизацией и с сопутствующей ХОБЛ, у больных 2-й группы - с сопутствующими тиреоидитом и гипертонической болезнью, в 3-й группе - при легкой форме БА и сопутствующем остеохондрозе позвоночника,

Таблица 2

Клиническая характеристика групп больных

\begin{tabular}{|c|c|c|c|c|c|c|c|c|c|c|c|}
\hline \multirow{2}{*}{ Группа } & \multicolumn{2}{|c|}{ Пол } & \multirow{2}{*}{$\begin{array}{c}\text { Средний } \\
\text { возраст, лет }\end{array}$} & \multirow{2}{*}{$\begin{array}{c}\text { Среднее число } \\
\text { приступов диспноэ } \\
\text { в сутки }\end{array}$} & \multicolumn{2}{|c|}{ Тяжесть БА } & \multicolumn{2}{|c|}{ Фаза БА } & \multicolumn{3}{|c|}{ Давность БА } \\
\hline & $M, \%$ & ж, \% & & & $\begin{array}{c}\text { легкая, } \\
\%\end{array}$ & $\begin{array}{c}\text { средняя, } \\
\%\end{array}$ & $\begin{array}{c}\text { обострение, } \\
\%\end{array}$ & $\begin{array}{c}\text { неполная } \\
\text { ремиссия, \% }\end{array}$ & $\begin{array}{c}<5 \text { лет, } \\
\%\end{array}$ & $\begin{array}{c}\text { 5-10 лет, } \\
\%\end{array}$ & $\begin{array}{c}>10 \text { лет, } \\
\%\end{array}$ \\
\hline $1 A$ & 65,7 & 34,3 & 42,7 & $3,1 \pm 0,6$ & 14,3 & 85,7 & 31,4 & 68,5 & 31,4 & 34,3 & 34,3 \\
\hline 15 & 33,9 & 66,1 & 41,8 & $4,2 \pm 0,9$ & 16,9 & 83,1 & 18,6 & 81,5 & 35,6 & 45,8 & 18,7 \\
\hline 1B & 28,6 & 71,4 & 47,1 & $3,8 \pm 1,2$ & 0 & 100 & 0 & 100 & 36,2 & 58,4 & 5,4 \\
\hline $2 A$ & 35,5 & 64,5 & 44,1 & $2,1 \pm 0,5$ & 38,7 & 61,3 & 54,8 & 45,2 & 61,3 & 16,1 & 22,6 \\
\hline 25 & 17,6 & 82,4 & 43,8 & $2,8 \pm 0,7$ & 29,4 & 70,6 & 38,2 & 61,8 & 50 & 29,4 & 20,6 \\
\hline 3 & 31,4 & 68,6 & 41,2 & $3,5 \pm 0,5$ & 5,7 & 94,3 & 20 & 80 & 31,4 & 51,4 & 17,1 \\
\hline 4 & 32 & 68 & 43,4 & $3,9 \pm 0,9$ & 12 & 88 & 36 & 64 & 48 & 20 & 32 \\
\hline 5 & 36 & 64 & 49,1 & $4,1 \pm 0,4$ & 30 & 70 & 32 & 68 & 46 & 24 & 30 \\
\hline сравнения & 34,3 & 65,7 & 43,8 & $1,9 \pm 0,7$ & 34,4 & 65,6 & 6,3 & 93,7 & 37,5 & 43,8 & 18,8 \\
\hline
\end{tabular}


Таблица 3

Клиническая эффективность лечения больных БА в различных группах

\begin{tabular}{|c|c|c|c|c|c|c|c|c|c|c|c|}
\hline \multirow[b]{2}{*}{ Группа } & \multicolumn{4}{|c|}{ Эффективность лечения, \% } & \multirow[b]{2}{*}{ Ухудшение } & \multirow[b]{2}{*}{$\begin{array}{c}\text { Уменьшение } \\
\text { числа присту- } \\
\text { пов, в разы }\end{array}$} & \multicolumn{5}{|c|}{ В отдаленном периоде } \\
\hline & $\begin{array}{c}\text { Общая } \\
\text { эффектив- } \\
\text { ность }\end{array}$ & $\begin{array}{c}\text { Значи- } \\
\text { тельное } \\
\text { улучшение }\end{array}$ & Улучшение & $\mid \begin{array}{c}\text { Без } \\
\text { динамики }\end{array}$ & & & $\begin{array}{c}\text { Снижение } \\
\text { дозы бронхо- } \\
\text { литиков, в разы }\end{array}$ & $\begin{array}{c}\text { Дальнейшее } \\
\text { улучшение, } \\
\%\end{array}$ & $\begin{array}{c}\text { Стабильное } \\
\text { состояние } \\
>12 \text { мес., \% }\end{array}$ & $\begin{array}{c}\text { Стабильное } \\
\text { состояние } \\
\text { 6-12 мес., \% }\end{array}$ & $\begin{array}{l}\text { Стабильное } \\
\text { состояние } \\
<6 \text { мес., \% }\end{array}$ \\
\hline $1 A$ & 80 & 42,8 & 37,2 & 20 & 0 & 3,1 & 4,1 & 23,5 & 64,7 & - & 11,8 \\
\hline 15 & 74,6 & 30,5 & 44,1 & 16,9 & 8,5 & 2,3 & 3,1 & - & 80 & 8 & 12 \\
\hline 1B & 14,3 & 0 & 14,3 & 42,9 & 42,9 & нет & нет & - & - & - & - \\
\hline $2 A$ & 93,5 & 6,5 & 87,1 & 6,5 & 0 & 3,2 & 3,4 & - & 13 & 62,5 & 24,5 \\
\hline 25 & 79,4 & 5,9 & 73,5 & 20,6 & 0 & 3,4 & 3 & 4,5 & 12 & 59,5 & 24 \\
\hline 3 & 68,6 & 0 & 68,6 & 22,8 & 8,6 & 1,9 & 2,4 & - & 23,8 & 66,7 & 9,5 \\
\hline 4 & 80 & 28 & 52 & 16 & 4 & 2,7 & 3,7 & 14,9 & 76,5 & 2,7 & 5,9 \\
\hline 5 & 82 & 36 & 46 & 16 & 2 & 3,4 & 2,7 & 16,6 & 66,7 & 16,6 & - \\
\hline сравнения & я 50 & 6,3 & 43,7 & 40,7 & 9,3 & 1,1 & 1,1 & - & - & - & - \\
\hline
\end{tabular}

в 4-й - при сопутствующих поллинозе, артериальной гипертензии и ИБС, а в 5-й - у больных с сопутствующими поллинозом и артериальной гипертензией.

Дифференцированный анализ эффективности методик показал, что комбинированное воздействие ЭМВ трансцеребрально и на область проекции селезенки и криомассажа более выражено у больных с экзогенной БА, причем криомассаж более эффективен у больных в фазу неполной ремиссии. Комбинированное воздействие ЭМВ трансцеребрально и на область проекции надпочечников, СМТ-электросон, сильвинитовая спелеотерапия и ИГТ эффективны как при экзогенной, так и при эндогенной БА, причем ИГТ в большей степени эффективна у больных в фазу неполной ремиссии заболевания.

\section{Динамика лабораторных показателей}

Показатели клинического и биохимического анализа крови больных БА в целом характеризовались большой вариабельностью. При этом отмечена значительная доля пациентов с исходной эозинофилией и ускоренной СОЭ. После курсов лечения ни в одной из групп больных в целом не происходили направленные достоверные изменения, однако исходно повышенные показатели изменялись существенно (табл. 4), что в определенной мере свидетельствовало о противовоспалительном действии процедур разной степени выраженности. В группе сравнения не изменялись даже исходно повышенные показатели.

В 5-й группе дополнительно исследовали мокроту, оценивая ее характер, наличие лейкоцитов, эозинофилов, эпителия, бактериальной и грибковой флоры. После курса сильвинитовой спелеотерапии произошла положительная динамика практически по всем параметрам (рис. 1), что демонстрировало противовоспалительный эффект, включающий в себя антиаллергический и бактериостатический компоненты.

Таблица 4 Достоверная динамика исходно повышенных лабораторных показателей

а) При трансцеребральных воздействиях ( $M \pm m, P<0,05)$

\begin{tabular}{|c|c|c|c|c|c|c|c|c|}
\hline \multirow[t]{2}{*}{ Показатели } & \multicolumn{8}{|c|}{ Группы больных (левый столбец - до курса, правый - после курса) } \\
\hline & \multicolumn{2}{|c|}{$1 \mathrm{~A}$} & \multicolumn{2}{|c|}{15} & \multicolumn{2}{|c|}{$2 A$} & \multicolumn{2}{|c|}{25} \\
\hline Лейкоциты, $10^{3}$ кл. / п. 3. & $9,8 \pm 1,8$ & $6,9 \pm 2,4$ & $9,6 \pm 2,1$ & $7,2 \pm 0,9$ & - & - & - & - \\
\hline Лимфоциты, \% & - & - & - & - & $46,1 \pm 1,8$ & $37,6 \pm 2,4$ & - & - \\
\hline Эозинофилы, \% & $6,2 \pm 0,8$ & $4,3 \pm 0,6$ & $10,0 \pm 2,1$ & $4,3 \pm 1,4$ & $8,6 \pm 1,0$ & $5,3 \pm 0,8$ & $8,7 \pm 1,4$ & $5,4 \pm 1,3$ \\
\hline СОЭ, мм / ч & - & - & $20,8 \pm 2,4$ & $13,6 \pm 1,8$ & - & - & - & - \\
\hline СРБ, у. e. & - & - & - & - & - & - & $1,8 \pm 0,2$ & $0,9 \pm 0,2$ \\
\hline Церулоплазмин, г / л & - & - & - & - & $0,45 \pm 0,03$ & $0,38 \pm 0,02$ & - & - \\
\hline Гистамин, мкмоль / л & - & - & $0,74 \pm 0,14$ & $0,49 \pm 0,11$ & - & - & - & - \\
\hline Серотонин, мкмоль / л & - & - & - & - & $1,08 \pm 0,07$ & $0,72 \pm 0,04$ & $0,80 \pm 0,05$ & $0,66 \pm 0,03$ \\
\hline
\end{tabular}

б) При воздействиях криомассажем, ИГТ и спелеотерапии

\begin{tabular}{|c|c|c|c|c|c|c|}
\hline & \multicolumn{2}{|c|}{3} & \multicolumn{2}{|c|}{4} & \multicolumn{2}{|c|}{5} \\
\hline Эозинофилы, \% & $5,6 \pm 0,8$ & $3,4 \pm 0,4$ & $7,3 \pm 1,2$ & $2,4 \pm 1,4$ & $6,3 \pm 1,0$ & $3,2 \pm 0,4$ \\
\hline Палочкоядерные л., \% & - & - & - & - & $1,5 \pm 0,3$ & $0,8 \pm 0,2$ \\
\hline Соэ, мм / ч & $23,5 \pm 4,3$ & $13,1 \pm 2,9$ & $23,0 \pm 4,1$ & $14,1 \pm 3,9$ & $20,8 \pm 2,8$ & $14,0 \pm 1,9$ \\
\hline
\end{tabular}




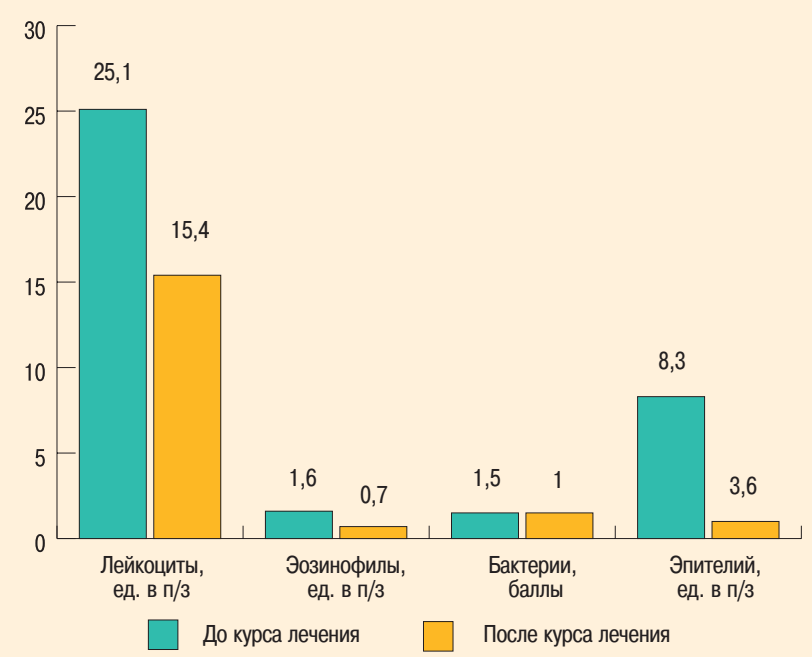

Рис.1. Изменение показателей анализа мокроты под влиянием сильвинитовой спелеотерапии

\section{Изменение иммунологических показателей}

Противовоспалительное действие и эффект вторичной профилактики обострений могут быть связаны с обнаруженным существенным влиянием процедур на иммунную систему больных, которое в целом можно определить как нормализующее. У больных БА в целом не отмечено направленного изменения изучавшихся показателей в среднем, однако у подавляющего большинства отмечены существенные колебания отдельных показателей по сравнению со здоровыми лицами, что в определенной мере свиде- тельствовало о дискоординации иммунной системы. Это может быть объяснено преморбидными дефектами в иммунной системе, антигенной стимуляцией различной степени выраженности и фазностью протекания аллергического воспаления в бронхах.

Результаты исследований в группах 1А и 1Б продемонстрировали существенную динамику первично измененных показателей (табл. 5, 6).

У больных группы 1Б не только снизилось количество прекоммитированных лимфоцитов в РБТЛ с ФГА, в среднем - с $1272,4 \pm 128,1$ до 941,1 \pm 96,7 абс. / мкл $(p<0,05)$, но и повысился иммунорегуляторный индекс стимуляции $(p<0,05)$. Это свидетельствовало о том, что на фоне снижения аллергической "настроенности" больных повышались функциональные возможности лимфоцитов, т. е. иммунная система демонстрировала более адекватную готовность к ответу на антигенный стимул. Показатели гуморального иммунитета существенно не изменились. Совокупность полученных данных позволяет рассматривать исследованные методики в качестве эффективных средств устранения дискоординации в иммунной системе больных БА, что имеет большое значение в реализации общего лечебного эффекта.

В группе 2А после курса лечения в целом повысился только иммунорегуляторный индекс с 0,86 \pm 0,1 до $1,11 \pm 0,1(p<0,05)$. Динамика остальных показателей также зависела от исходных значений. Отмечено снижение исходно повышенного абсолютного уровня Т-лимфоцитов с $1405,2 \pm 46,5$ до 761, $1 \pm 86,8 \times 10^{9} /$ л $(p<0,001)$ и повышение исходно сниженного относительного уровня с 41,4 $\pm 2,3$ до 55,4 $\pm 3,0 \%(p<0,001)$. Повысился с $15,1 \pm 0,7$ до $21,9 \pm 1,9 \%(p<0,01)$

Таблица 5

Изменение иммунологических показателей под влиянием курса комбинированного воздействия ЭМВ трансцеребрально и на область проекиии надпочечников ( $M \pm m, n=35)$

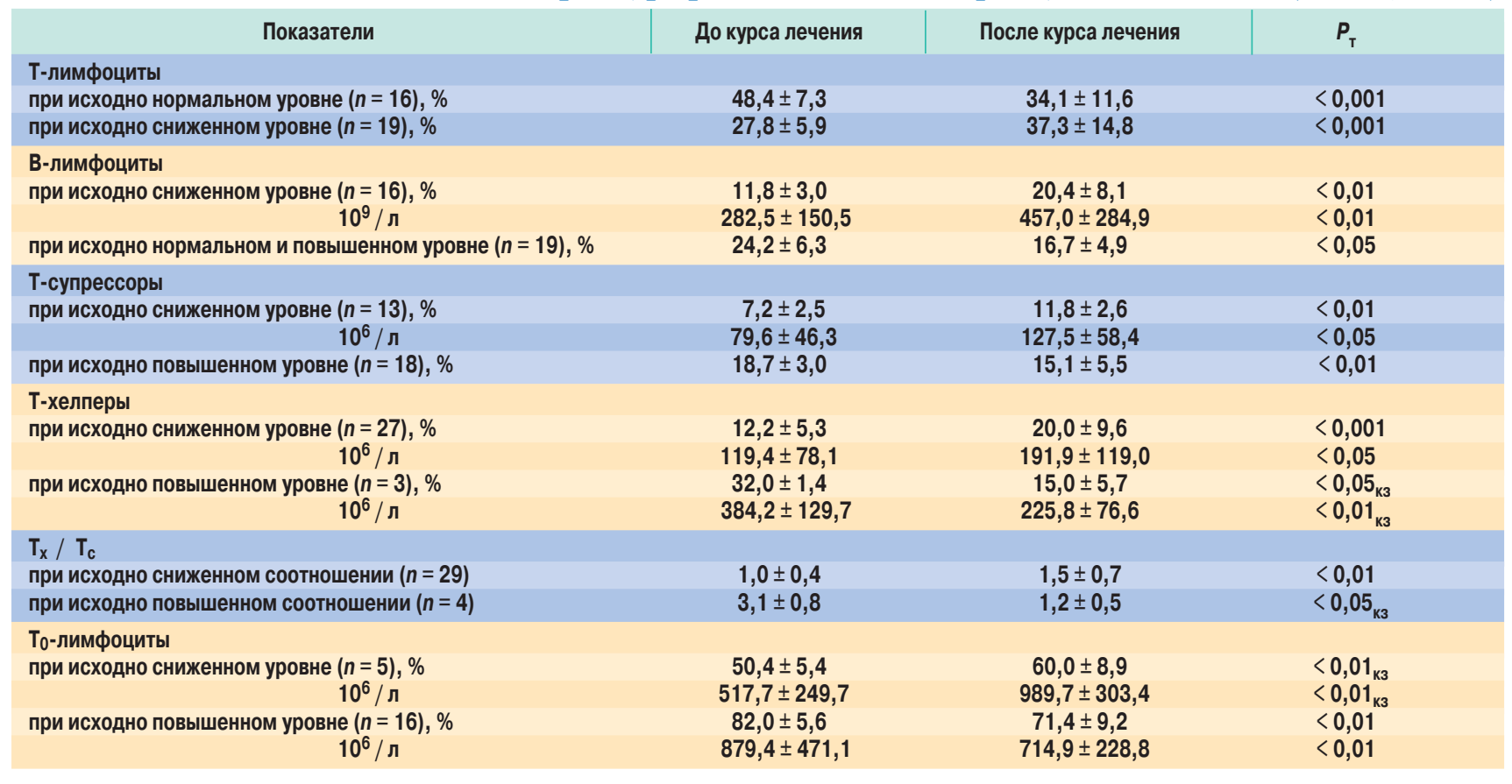


Изменение иммунологических показателей под влиянием курса комбинированного воздействия ЭМВ трансцеребрально и на область проекции селезенки $(M \pm m, n=53)$

\begin{tabular}{|c|c|c|c|}
\hline Показатели & До курса лечения & После курса лечения & $P_{\mathrm{T}}$ \\
\hline \multicolumn{4}{|l|}{ Т-лимфоциты } \\
\hline $\begin{array}{c}\text { при исходно сниженном уровне }(n=34), \% \\
10^{9} / \pi\end{array}$ & $\begin{array}{c}36,3 \pm 2,3 \\
587,4 \pm 105,2\end{array}$ & $\begin{array}{c}39,8 \pm 1,6 \\
850,4 \pm 143,8\end{array}$ & $\begin{array}{l}<0,001 \\
<0,001\end{array}$ \\
\hline $\begin{array}{l}\text { В-лимфоциты } \\
\text { при исходно сниженном уровне }(n=38), \% \\
10^{9} / л\end{array}$ & $\begin{array}{c}16,2 \pm 2,3 \\
309,2 \pm 115,7\end{array}$ & $\begin{array}{c}23,3 \pm 4,1 \\
476,6 \pm 185,9\end{array}$ & $\begin{array}{l}<0,01 \\
<0,01\end{array}$ \\
\hline Т-супрессоры, \% & $\begin{array}{c}15,5 \pm 6,4 \\
119,6 \pm 51,1\end{array}$ & $\begin{array}{c}17,8 \pm 3,7 \\
138,1 \pm 46,1\end{array}$ & $\begin{array}{l}<0,05 \\
<0,05\end{array}$ \\
\hline $\begin{array}{l}\text { T-хелперы } \\
\text { при исходно сниженном уровне }(n=30), \% \\
10^{6} / л\end{array}$ & $\begin{array}{c}16,5 \pm 5,2 \\
111,0 \pm 61,1\end{array}$ & $\begin{array}{c}25,3 \pm 6,9 \\
149,0 \pm 91,3\end{array}$ & $\begin{array}{l}<0,01 \\
<0,05\end{array}$ \\
\hline $\mathrm{T}_{\mathrm{x}} / \mathrm{T}_{\mathrm{c}}$ & $1,4 \pm 0,4$ & $1,6 \pm 0,6$ & - \\
\hline $\begin{array}{l}\text { T0-лимфоциты } \\
\text { при исходно сниженном уровне }(n=22), \% \\
10^{6} / \text { л }\end{array}$ & $\begin{array}{c}50,3 \pm 5,1 \\
341,6 \pm 99,3\end{array}$ & $\begin{aligned} 55,0 & \pm 3,9 \\
403,4 & \pm 92,8\end{aligned}$ & $\begin{array}{l}<0,05 \\
<0,05\end{array}$ \\
\hline
\end{tabular}

исходно сниженный уровень Т-хелперов, и снизился исходно повышенный уровень Т-супрессоров с $24,0 \pm 1,1$ до $20,1 \pm 1,3 \%(p<0,05)$ и с $247,8 \pm 13,7$ до $168,3 \pm 19,5 \times 10^{6} /$ л $(p<0,01)$, а также повысилось исходно сниженное количество $\mathrm{T}_{0}$-лимфоцитов с $375,0 \pm 18,6$ до 489,5 $\pm 43,4 \times 10^{6} / л(p<0,02)$ и снизилось исходно повышенное содержание $\mathrm{IgG}$ в крови с 13,6 $\pm 0,3$ до 12,3 $\pm 0,5$ г / л $(p<0,05)$.

Подобные тенденции отмечены и у больных группы 2Б. Уровень Т-лимфоцитов повышался с 40,1 \pm 1,3 до $47,1 \pm 3,0 \%(p<0,05)$ и с $670,9 \pm 36,0$ до 828,6 $\pm 77,2$ $\times 10^{9} /$ л $(p<0,01)$ у больных с исходно низкими показателями. Сниженное относительное содержание Т-хелперов повысилось с 16,0 \pm 0,8 до 19,5 $\pm 1,2 \%$ $(p<0,01)$, а абсолютное содержание Т-супрессоров повысилось с 105,6 \pm 5,8 до 151,2 $\pm 20,9 \times 10^{6} /$ л $(p<0,01)$. Повышенный стартовый уровень $\mathrm{T}_{0}$-лимфоцитов снижался с 758,5 \pm 45,7 до 453,5 $\pm 61,1 \times 10^{6} /$ л $(p<0,02)$, а пониженный - повышался с 372,3 \pm 19,7 до 466,5 \pm $31,2 \times 10^{6} /$ л $(p<0,02)$. После курса лечения достоверно возрастала с $523 \pm 53$ до $1020 \pm 178$ имп. / мин $(p<0,01)$ исходно сниженная спонтанная пролиферативная активность лимфоцитов в тесте РБТЛ, а также сниженная митогенстимулированная активность $(p<0,02)$. Показатели гуморального звена иммунитета существенно не изменились, вместе с тем, исходно повышенный у большинства больных (72 \%) уровень ЦИК, косвенно свидетельствующий об активности аутоиммунного воспаления, имел тенденцию к снижению с 0,18 $\pm 0,01$ до 0,15 $\pm 0,001$ у. е. $(p<0,05)$. Степень функциональной активности ЩЖ не оказывала существенного влияния на динамику иммунологических показателей.

Множественный корреляционный анализ позволил выявить переход от "линейного" к более адекватному "решетчатому" типу взаимодействий иммунологических показателей в обеих группах (рис. 2).

У больных 3-й группы отмечено снижение уровня Т-лимфоцитов (с 53,8 $\pm 4,1$ до 47,2 $\pm 4,8 \%, p<0,05$ ) и В-лимфоцитов (с 18,8 $\pm 2,8$ до $15,1 \pm 1,7 \%, p<0,05)$, происходившее в основном за счет пациентов с исходно повышенными показателями, можно рассматривать как снижение готовности организма к неадекватной гиперергической реакции на антигены, в т. ч. и на атопические аллергены. Непосредственное влияние процедур криомассажа на иммунную систему может реализовываться через активизацию находящихся в коже "периферийных" клеток иммунной системы - клеток Лангерганса.

В результате курса ИГТ у больных БА достоверно повышался уровень Т-лимфоцитов в крови с 48,6 \pm 6,7 до $56,4 \pm 9,0 \%\left(p_{\mathrm{T}}<0,01\right)$, несколько повышался уровень Т-хелперов с 170,5 \pm 54,5 до 217,6 \pm 52,4 x 106 / л $\left(p_{\mathrm{T}}<0,05\right)$. Количество прекоммитированных лимфоцитов в РБТЛ имело тенденцию к снижению $(p=0,05)$.

При изучении гормонального профиля выявлено существенное влияние некоторых методик на содержание гормонов в крови. При исходно нормаль-

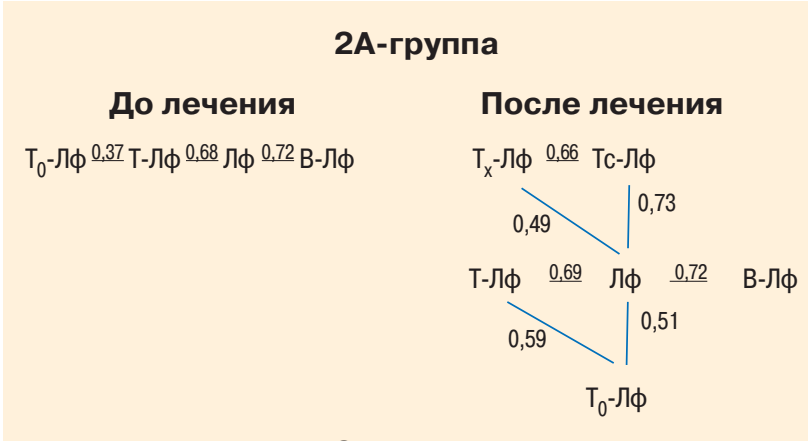

2А-группа

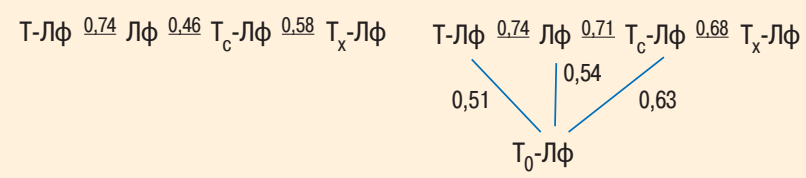
Над соединительными черточками указаны коэффициенты корреляции
между показателями

Рис. 2. Сравнительный анализ корреляционных взаимодействий в иммунной системе больных 2-й группы под влиянием трансцеребрального воздействия СМТ (группа 2А) 
Диналика показателей ФВДу больных БА под влиянием курса сильвинитовой спелеотерапии (M $\pm m, n=50)$

\begin{tabular}{|c|c|c|c|c|c|c|c|}
\hline Время исследования & ЖЕЛ, \% & ФЖЕЛ, \% & $0 \Phi B_{1}, \%$ & пос, $\%$ & $\mathrm{MOC}_{25}, \%$ & MOC $_{50}, \%$ & $\mathrm{MOC}_{75}, \%$ \\
\hline До лечения & $93,9 \pm 4,2$ & $83,6 \pm 4,0$ & $75,1 \pm 4,8$ & $74,2 \pm 5,3$ & $62,6 \pm 5,8$ & $48,3 \pm 5,4$ & $37,1 \pm 3,8^{*}$ \\
\hline После лечения & $104,4 \pm 3,9$ & $93,1 \pm 4,0$ & $88,1 \pm 5,0$ & $88,1 \pm 4,5$ & $76,6 \pm 5,2$ & $58,6 \pm 4,6$ & $46,0 \pm 4,4^{*}$ \\
\hline
\end{tabular}

Примечание: $P<0,001 ;{ }^{*}-P<0,05$.

ных уровнях гормонов в крови изменений практически не отмечалось, а динамика показателей наблюдалась только у лиц с исходно измененными показателями.

В частности, в группе 1А после курса лечения отмечено достоверное снижение исходно повышенных уровней ТТГ (с 7,64 \pm 1,55 до 6,33 \pm 3,28 нмоль / л; $\left.p_{\mathrm{T}}<0,05\right)$, кортизола (с $1027 \pm 309$ до $705 \pm 233$ нмоль $/$ л; $\left.p_{\mathrm{T}}<0,001\right)$ и альдостерона (с $1049 \pm 138$ до $985 \pm$ 464 нмоль / л; $\left.p_{\mathrm{T}}<0,05\right)$ и повышение исходно сниженных уровней кортизола (с $212 \pm 22$ до $387 \pm 153$ нмоль / л; $\left.p_{\mathrm{K} 3}<0,05\right)$ и АКТГ (с 1,4 \pm 0,4 до 15,6 \pm 8,4 нг / л; $\left.p_{\text {кз }}<0,05\right)$. У остальных больных уровень АКТГ даже несколько снизился (с 41,6 \pm 31,8 до 30,6 $\pm 24,2$ нг / л; $\left.p_{\text {т }}<0,01\right)$. При этом коэффициент корреляции между уровнями АКТГ и кортизола в крови вырос с 0,17 до 0,37 ( $p<0,005)$. Восстановление нормальных реципрокных взаимоотношений между АКТГ и кортизолом сопровождалось еще одним интересным феноменом. У больных с положительной клинической динамикой наблюдалась обратная связь между уровнями кортизола и В-лимфоцитов в периферической крови $(r=-0,56 ; p<0,01)$. У остальных больных эта связь отсутствовала, что в определенной мере может свидетельствовать о важной роли кортизолочувствительности лимфоцитов в реализации лечебного эффекта процедур.

У больных группы 2Б произошло повышение исходно сниженного уровня $\mathrm{T}_{4}$ с $83 \pm 9$ до $102 \pm$ 13 мкг / л $\left(p_{\mathrm{T}}<0,01\right)$ и снижение исходно повышенного уровня с $143 \pm 20$ до $117 \pm 20$ мкг / л $\left(p_{\mathrm{T}}<0,05\right)$. Такой результат может быть объяснен опосредованным влиянием на ЩЖ за счет нормализующего влияния на подкорковые центры через систему гипоталамус-гипофиз-ШЖ. В остальных группах эндокринные показатели существенно не изменялись.

Перестройка нейроэндокринноиммунных взаимоотношений в конечном счете снижает интенсивность аллергического воспаления в бронхах, что приводит к снижению их чувствительности и реактивности, уменьшению спазма, отека слизистой и вязкости мокроты и, соответственно, к улучшению мукоцилиарного клиренса. В итоге происходит улучшение скоростных показателей воздушного потока.

\section{Данные спирографических исследований}

За исключением больных 5-й группы, у которых сильвинитовая спелеотерапия приводила к улучшению практически всех основных спирографических показателей (табл. 7), в остальных группах в среднем значения достоверно не изменялись, что можно рассматривать как положительный фактор с учетом значительного снижения суммарной дозы бронхолитических препаратов.

Не менее важно улучшение исходно сниженных показателей (табл. 8) и сохранение значений показателей в отдаленный период в соответствии с клиническим состоянием. Опережение снижения доз медикаментов, потребных для купирования приступов, по сравнению со снижением среднесуточного числа приступов экспираторного диспноэ, свидетельствует также и об уменьшении выраженности приступов. Дополнительное седативное действие процедур не только снижает вероятность возникновения нейрогенных приступов экспираторного диспноэ, но и формирует правильный стереотип дыхания у больных БА за счет влияния на его нейровегетативное обеспечение.

У репрезентативной части больных 4-й группы были проведены ЭхоКГ и вариационная кардиоинтервалография (табл. 9). Исследования проводили не менее чем через 1 ч после процедуры ИГТ и не менее чем через 3 ч после последнего применения медикаментов, обладающих вегетотропным действием.

Несмотря на снижение дозы адреномиметиков, у больных БА наблюдалась отчетливая тенденция к увеличению симпатикотонических влияний, о чем

Таблииа 8

Динамика исходно сниженных спирографических показателей у некоторых групп больных $\left(M \pm m, P_{T}<0,05\right)$

\begin{tabular}{|c|c|c|c|c|c|c|c|c|c|c|c|c|}
\hline \multirow[t]{2}{*}{ Параметры } & \multicolumn{12}{|c|}{ Группа } \\
\hline & \multicolumn{2}{|c|}{$1 \mathrm{~A}$} & \multicolumn{2}{|c|}{15} & \multicolumn{2}{|c|}{$2 A$} & \multicolumn{2}{|c|}{25} & \multicolumn{2}{|c|}{3} & \multicolumn{2}{|c|}{4} \\
\hline ЖЕЛ, \% & - & - & - & - & $89,2 \pm 2,4$ & $96,0 \pm 3,5$ & $88,8 \pm 4,2$ & $95,3 \pm 3,6$ & - & - & - & - \\
\hline ФЖЕЛ, \% & - & - & - & - & $83,7 \pm 3,3$ & $90,6 \pm 2,9$ & $80,9 \pm 3,6$ & $84,1 \pm 3,4$ & - & - & - & - \\
\hline $0 \Phi \mathrm{B}_{1} /$ & & & & & & & & & & & & \\
\hline ФЖЕЛ, \% & $49,2 \pm 1,0$ & $55,7 \pm 1,6$ & $56,4 \pm 1,2$ & $65,7 \pm 1,6$ & - & - & - & - & - & - & $47,5 \pm 1,2$ & $57,8 \pm 1,6$ \\
\hline пос, \% & $36,7 \pm 1,8$ & $47,7 \pm 4,0$ & $43,6 \pm 1,7$ & $58,4 \pm 4,2$ & $53,7 \pm 2,3$ & $59,9 \pm 3,8$ & $42,9 \pm 6,2$ & $49,1 \pm 5,3$ & $51,7 \pm 4,2$ & $63,9 \pm 5,0$ & $40,4 \pm 2,0$ & $51,6 \pm 2,3$ \\
\hline $\mathrm{MOC}_{50}, \%$ & - & - & - & - & $47,2 \pm 5,4$ & $52,8 \pm 4,9$ & $41,2 \pm 5,6$ & $55,1 \pm 5,1$ & $46,4 \pm 3,8$ & $55,3 \pm 4,2$ & - & - \\
\hline $\mathrm{MOC}_{25}, \%$ & $25,6 \pm 1,4$ & $31,9 \pm 2,1$ & $29,6 \pm 1,6$ & $37,9 \pm 2,3$ & - & - & $29,6 \pm 4,5$ & $34,1 \pm 4,3$ & $36,1 \pm 4,3$ & $46,1 \pm 4,1$ & $28,7 \pm 2,1$ & $39,0 \pm 2,3$ \\
\hline
\end{tabular}


Динамика показателей ЭхоКГ и кардиоинтервалографии под влиянием курса ИГТ $(M \pm m, n=18)$

\begin{tabular}{|c|c|c|c|}
\hline Показатели & До лечения & После лечения & $P_{\mathrm{T}}$ \\
\hline Конечный диастолический размер левого желудочка, см & $4,85 \pm 0,28$ & $4,99 \pm 0,31$ & $<0,05$ \\
\hline Конечный систолический размер левого желудочка, см & $3,01 \pm 0,11$ & $2,84 \pm 0,07$ & $<0,05$ \\
\hline Сократимость миокарда, \% & $38,1 \pm 0,1$ & $41,2 \pm 0,2$ & $<0,05$ \\
\hline Ударный объем кровообращения, мл & $74,9 \pm 1,4$ & $76,2 \pm 2,0$ & - \\
\hline Минутный объем кровообращения, л / мин & $5,46 \pm 0,67$ & $5,54 \pm 0,45$ & - \\
\hline Фракция выброса, \% & $65,6 \pm 0,7$ & $72,3 \pm 1,2$ & $<0,01$ \\
\hline Размер правого желудочка, см & $1,35 \pm 0,06$ & $1,38 \pm 0,05$ & - \\
\hline Амплитуда моды, \% & $44,94 \pm 2,45$ & $50,27 \pm 1,83$ & $<0,05$ \\
\hline Индекс напряжения, у. е. & $125,8 \pm 39,6$ & $220,3 \pm 27,9$ & $<0,05$ \\
\hline
\end{tabular}

свидетельствовало возрастание показателей индекса напряжения и амплитуды моды в кардиоинтервалографических исследованиях, и увеличение мощности работы сердца, что свидетельствует о выраженном вегетотропном действии ИГТ.

\section{Заключение}

Полученные результаты в совокупности с литературными данными позволяют заключить, что в основе механизмов лечебного действия комбинированных воздействий ЭМВ и СМТ-электросна лежит нормализация нейроэндокринноиммунных взаимоотношений, обеспечивающая противовоспалительный, бронхолитический и седативный эффекты с длительным последействием и феноменом вторичной профилактики обострений БА.

Действие криомассажа связано со стрессовыми реакциями, изменением биомеханики дыхания, согласованной с кожными сосудами фазной реакции

Таблица 10

Особенности применения различных методик у больных БА

\begin{tabular}{|c|c|c|c|c|c|c|}
\hline Методика & $\begin{array}{c}\text { Прирост } \\
\text { эффективности } \\
\text { лечения }\end{array}$ & $\begin{array}{c}\text { Предпочтительные } \\
\text { варианты } \\
\text { течения БА }\end{array}$ & $\begin{array}{c}\text { Предикторы } \\
\text { эффективности } \\
\text { на сопутствующие } \\
\text { заболевания }\end{array}$ & $\begin{array}{c}\text { Положительное } \\
\text { влияние } \\
\text { положительного } \\
\text { эффекта }\end{array}$ & $\begin{array}{c}\text { Длительность } \\
\text { сохранения }\end{array}$ & $\begin{array}{c}\text { Специальные } \\
\text { показания }\end{array}$ \\
\hline $\begin{array}{l}\text { ЭМВ } \\
\text { трансцеребрально } \\
\text { и на область } \\
\text { проекции } \\
\text { надпочечников }\end{array}$ & $+30 \%$ & $\begin{array}{l}\text { Экзогенная и эндо- } \\
\text { генная, средней тяжести } \\
\text { в фазе обострения или } \\
\text { неполной ремиссии }\end{array}$ & $\begin{array}{l}\text { Иммунный } \\
\text { (субпопуляционный) } \\
\text { и гормональный } \\
\text { дисбаланс }\end{array}$ & $\begin{array}{l}\text { Дисфункция яичников, } \\
\text { вторичное бесплодие, } \\
\text { ревматические } \\
\text { заболевания }\end{array}$ & $\begin{array}{l}10-12 \text { мес. } \\
\text { у } 87 \% \\
\text { больных }\end{array}$ & $\begin{array}{l}\text { Относительная } \\
\text { надпочечниковая } \\
\text { недостаточность, } \\
\text { "астматическая } \\
\text { триада" }\end{array}$ \\
\hline $\begin{array}{l}\text { ЭМВ } \\
\text { трансцеребрально } \\
\text { и на область } \\
\text { проекции } \\
\text { селезенки }\end{array}$ & $+24,6 \%$ & $\begin{array}{l}\text { Экзогенная } \\
\text { средней тяжести } \\
\text { в фазе обострения } \\
\text { или неполной ремиссии }\end{array}$ & $\begin{array}{l}\text { Т-клеточный дефицит, } \\
\text { дедифференцировка } \\
\text { Т-лимфоцитов } \\
\text { и снижение } \\
\text { функциональной } \\
\text { активности } \\
\text { лимфоцитов }\end{array}$ & ХОБЛ & $\begin{array}{l}\text { 6-8 мес. } \\
\text { у } 80 \% \\
\text { больных }\end{array}$ & $\begin{array}{l}\text { Клеточный } \\
\text { иммунодефицит, } \\
\text { сопутствующее } \\
\text { неспецифическое } \\
\text { воспаление } \\
\text { в бронхах }\end{array}$ \\
\hline Криомассаж & $+18,4 \%$ & $\begin{array}{l}\text { Экзогенная легкая } \\
\text { или средней тяжести } \\
\text { в фазе неполной } \\
\text { ремиссии }\end{array}$ & $\begin{array}{l}\text { Адекватная } \\
\text { терморегуляция, } \\
\text { нарушение } \\
\text { биомеханики } \\
\text { дыхания }\end{array}$ & $\begin{array}{l}\text { Остеохондроз } \\
\text { позвоночника }\end{array}$ & $\begin{array}{l}\text { 5-6 мес. } \\
\text { у } 76 \% \\
\text { больных }\end{array}$ & $\begin{array}{l}\text { Неврологические } \\
\text { и мышечно- } \\
\text { трофические } \\
\text { проявления } \\
\text { остеохондроза } \\
\text { позвоночника }\end{array}$ \\
\hline ИГт & $+30 \%$ & $\begin{array}{l}\text { Экзогенная } \\
\text { и эндогенная } \\
\text { средней тяжести } \\
\text { в фазе неполной } \\
\text { ремиссии }\end{array}$ & нет & $\begin{array}{l}\text { Сердечно- } \\
\text { сосудистые } \\
\text { заболевания, } \\
\text { ХОБЛ, } \\
\text { аллергческий ринит }\end{array}$ & $\begin{array}{l}10-12 \text { мес. } \\
\text { у } 91 \% \\
\text { больных }\end{array}$ & $\begin{array}{l}\text { ИБС, } \\
\text { стенокардия } \\
\text { напряжения 1-2 ФК, } \\
\text { гипертоническая } \\
\text { болезнь І-ІІ ст. }\end{array}$ \\
\hline $\begin{array}{l}\text { Сильвинитовая } \\
\text { спелеотерапия }\end{array}$ & $+32 \%$ & $\begin{array}{l}\text { Экзогенная } \\
\text { и эндогенная, } \\
\text { средней тяжести } \\
\text { в фазе обострения } \\
\text { или неполной } \\
\text { ремиссии }\end{array}$ & нет & $\begin{array}{l}\text { ХОБЛ, } \\
\text { аллергический } \\
\text { ринит }\end{array}$ & $\begin{array}{l}10-12 \text { мес. } \\
\text { у } 83 \% \\
\text { больных }\end{array}$ & $\begin{array}{l}\text { Отмена } \\
\text { пероральных } \\
\text { кортикостероидов, } \\
\text { сопутствующий } \\
\text { аллергический } \\
\text { ринит }\end{array}$ \\
\hline
\end{tabular}


гладкой мускулатуры бронхов (спазм-расслабление), мобилизацией в кожу эозинофильных лейкоцитов и формированием альтернативной доминанты. ИГТ приводит к немедленной мобилизации компенсаторных механизмов газообмена, в т. ч. путем снижения бронхиальной чувствительности и реактивности, и симпатикотонического действия. Противовоспалительное действие реализуется за счет снижения в условиях гипоксии интенсивности перекисного окисления липидов и умеренной иммунной модуляции.

Благоприятные для больных БА параметры спелеокамеры (низкая бактериальная обсемененность, аллергенная стерильность, стабильность температуры и влажности) наряду с повышенной за счет радиоактивного излучения изотопа $\mathrm{K}^{40}$ и трибоэлекгрического эффекта аэроионизации обеспечивают противовоспалительное, бактериостатическое, бронхо- и секретолитическое и седативное действие процедур. Основные эффекты изученных методик схематично представлены в табл. 10 и 11.

\section{Выводы}

1. Применение различных физических факторов (комбинированное воздействие ЭМВ трансцеребрально и на области проекции надпочечников и селезенки, СМТ-элетросна, криомассажа, ИГТ и сильвинитовой спелеотерапии) повышает эффективность лечения больных БА легкого течения и средней тяжести в среднем на 18-36 \%, по сравнению с изолированной базисной медикаментозной терапией, обладает длительным последействием (6-12 мес.) и эффектом вторичной профилактики в отношении обострений.

2. При эндогеннной и эКзогенной БА в фазе обострения и неполной ремиссии клинически эффективно назначение комбинированного воздействия ЭМВ трансцеребрально и на область проекции надпочечников, СМТ-электросна и сильвинитовой спелеотерапии; ИГТ эффективна в фазу неполной ре- миссии. При экзогенной БА в фазе обострения и неполной ремиссии эффективно назначение комбинированного воздействия ЭМВ трансцеребрально и на область проекции селезенки, а назначение криомассажа - в фазу неполной ремиссии.

3. Комбинированное воздействие ЭМВ трансцеребрально и на область проекции надпочечников нормализует уровни АКТГ, ТТГ, кортизола и альдостерона в крови, восстанавливает реципрокные взаимоотношения между АКТГ и кортизолом и кортизолочувствительность лимфоцитов; СМТ-электросон нормализует уровень тироксина в крови.

4. Комбинированное воздействие ЭМВ трансцеребрально на области проекции надпочечников и селезенки, СМТ-электросон нормализацуют исходно измененные уровни Т- и В-лимфоцитов, ликвидируют субпопуляционный дисбаланс и дедифференцировку лимфоцитов. Криомассаж снижает уровни Т- и В-лимфоцитов в крови, а ИГТ повышает уровни Т-лимфоцитов и Т-хелперов. Комбинированное воздействие ЭМВ трансцеребрально и на область проекции селезенки и СМТ-электросон восстанавливают первичную функциональную и митогенную активность лимфоцитов. СМТ-электросон снижает исходно повышенный уровень IgG и ЦИК в крови и восстанавливает ассоциативность иммунологических показателей.

5. Противовоспалительное действие изученных физических факторов подтверждается помимо влияния на эндокринную и иммунную систему снижением эозинофилии и лейкоцитоза в крови, замедлением СОЭ. Комбинированное воздействие ЭМВ трансцеребрально и на область проекции селезенки снижает уровень гистамина и альбумино-глобулиновый коэффициент, СМТ-электросон нормализует уровни серотонина, церулоплазмина и СРБ в крови, а спелеотерапия значительно улучшает характер отделяемой мокроты за счет

Таблица 11

Основные эффекты изученных методик

\begin{tabular}{|c|c|c|c|c|c|c|c|c|c|}
\hline \multirow[b]{2}{*}{ Методика } & \multicolumn{9}{|c|}{ Эффект } \\
\hline & $\begin{array}{l}\text { Иммунная } \\
\text { модуляция }\end{array}$ & $\begin{array}{l}\text { Противо- } \\
\text { воспали- } \\
\text { тельный }\end{array}$ & $\begin{array}{c}\text { Улучшение } \\
\text { мукоцилиарного } \\
\text { клиренса }\end{array}$ & $\begin{array}{l}\text { Эндокринная } \\
\text { модуляция }\end{array}$ & Седативный & $\begin{array}{c}\text { Улучшение } \\
\text { бронхиальной } \\
\text { проходимости }\end{array}$ & $\begin{array}{l}\text { Гемо- } \\
\text { динами- } \\
\text { ческий }\end{array}$ & $\begin{array}{l}\text { Вегетативная } \\
\text { регуляция }\end{array}$ & $\begin{array}{c}\text { Уменьшение } \\
\text { атопической } \\
\text { сенсибилизации }\end{array}$ \\
\hline $\begin{array}{l}\text { ЭМВ трансцеребрально } \\
\text { и на область проекции } \\
\text { надпочечников }\end{array}$ & ++ & ++ & ++ & ++ & + & + & \pm & + & + \\
\hline $\begin{array}{l}\text { ЭМВ трансцеребрально } \\
\text { и на область } \\
\text { проекции селезенки }\end{array}$ & ++ & ++ & ++ & - & + & + & \pm & + & + \\
\hline СМТ-электросон & + & t+ & - & + & t+ & + & + & t+ & + \\
\hline Криомассаж & + & + & + & - & + & + & + & + & + \\
\hline $\begin{array}{l}\text { Интервальная } \\
\text { гипоксическая } \\
\text { тренировка }\end{array}$ & + & + & ++ & не изучено & + & + & ++ & ++ & + \\
\hline $\begin{array}{l}\text { Сильвинитовая } \\
\text { спелеотерапия }\end{array}$ & не изучено & +t & ++ & не изучено & t+ & t+ & + & + & + \\
\hline
\end{tabular}


снижения числа лейкоцитов, эозинофилов и эпителиальных клеток и бактериальной обсемененности.

6. Противовоспалительное действие изученных физических факторов в совокупности с седативным, вегетотропным и мукокинетическим действием обеспечивает бронхолитический эффект, что подтверждается приростом скоростных показателей воздушного потока, по данным спирографии. Применение воздействия ЭМВ трансцеребрально и на область проекции надпочечников, СМТэлектросна и спелеотерапии приводит к увеличению объемных спирометрических показателей.

7. Особенности действия физических факторов позволяют дифференцированно подходить к их назначению, исходя из индивидуальных особенностей течения БА у конкретного больного и наличия сопутствующей патологии. Комбинированное воздействие ЭМВ трансцеребрально и на область проекции надпочечников в большей степени показано больным БА с относительной надпочечниковой недостаточностью и больным с простагландиновым механизмом формирования бронхоспазма; комбинированное воздействие ЭМВ трансцеребрально и на область проекции селезенки - больным экзогенной БА с выраженным клеточным иммунодефицитом.
СМТ-электросон является методикой выбора у больных БА с сопутствующим тиреоидитом; криомассаж эффективен при адекватной терморегуляции и сопутствующих нейромышечных проявлениях остеохондроза позвоночника; ИГТ за счет мягкого симпатикотонического действия более эффективна при сопутствующих сердечно-сосудистых расстройствах, ограничивающих прием адреномиметиков. Сильвинитовая спелеотерапия за счет отсутствия специфических противопоказаний, благоприятного влияния на течение ХОБЛ и аллергического ринита может рассматриваться как одно из универсальных средств лечения больных БА и вторичной профилактики обострений.

\section{Литература}

1. Глобальная стратегия лечения и профилактики бронхиальной астмы. Пересмотр 2002 г.: Пер. с англ. М.: Атмосфера; 2002.

2. Боголюбов В.М. (ред.). Медицинская реабилитация (Руководство для врачей). М.; Пермь: ИПК "Звезда"; 1998; т. $1-3$.

3. Физические методы лечения в пульмонологии / Клячкин Л.М., Малявин А.Г., Пономаренко Г.Н. и др. СПб.: СЛП; 1997. 